\title{
High ratio of interfollicular CD8/FOXP3-positive regulatory $T$ cells is associated with a high FLIPI index and poor overall survival in follicular lymphoma
}

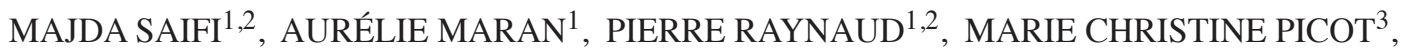 \\ PHILIPPE QUITTET $^{4}$, GUILLAUME CARTRON ${ }^{2,4}$, JEAN FRANÇOIS ROSSI ${ }^{2,4}$ and VALÉRIE COSTES ${ }^{1,2}$ \\ ${ }^{1}$ Department of Pathology, ${ }^{2}$ INSERM U847, ${ }^{3}$ Medical Information Department, \\ ${ }^{4}$ Onco-Hematology and Biotherapy Department, CHU Montpellier, 34295 Montpellier Cedex 5, France
}

Received June 25, 2010; Accepted August 25, 2010

DOI: $10.3892 / \mathrm{etm} .2010 .146$

\begin{abstract}
Several studies have highlighted the importance of the microenvironment in the behaviour of follicular lymphoma (FL). We conducted an immunohistochemical analysis to assess the role of different cell subpopulations, i.e. CD8, CD68 and forkhead box protein P3 (FOXP3)-positive regulatory $\mathrm{T}$ cells (Treg cells) in 84 lymph nodes of 58 patients with FL (58 at diagnosis, 26 at relapse). Since the overall effect of Tregs is considered to depend on their number in relation to $\mathrm{CD} 8^{+}$effector $\mathrm{T}$ cells, we determined the corresponding ratio for each patient and correlated the results with clinical parameters. The interfollicular $\mathrm{CD} 8 / \mathrm{FOXP}^{+}$cell ratio was significantly higher in patients with histological grade 3 tumours (2.04 vs. 1.63) and with a high risk FLIPI index (2.99 vs. 1.53) compared to those with grade 1-2 tumours or a low-intermediate FLIPI index. Similar results were obtained for the follicular $\mathrm{CD}^{+} / \mathrm{FOXP}^{+}$cell ratio. The interfollicular CD8/FOXP3 ratio was found to have prognostic value [a 5 -year overall survival (OS) of 82 vs. $59 \%$ for a ratio of \pm 1.68 ] In addition, an interfollicular FOXP3 ${ }^{+}$cell number of more than 86 cells $/ \mathrm{mm}^{2}$ was correlated with a more favourable outcome $(\mathrm{p}=0.03)$. When patients at diagnosis and relapse were compared, a significant difference $(\mathrm{p}=0.05)$ in the localization (interfollicular vs. intrafollicular) of $\mathrm{FOXP}^{+}$cells was observed. The CD8/FOXP3 ratio in the interfollicular areas was significantly different (1.66 at diagnosis vs. 2.2 at relapse, $\mathrm{p}=0.05)$. The presence of a small number of $\mathrm{FOXP}^{+}$cells with a high CD8/FOXP3 ratio is probably the indicator of an active immune response during tumour development, with lymphoma cells acting as targets or bystanders.
\end{abstract}

Correspondence to: Dr Valérie Costes, Department of Pathology, CHU Montpellier, 80 Av A. Fliche, 34295 Montpellier Cedex 5, France

E-mail: v-costes_martineau@chu-montpellier.fr

Key words: FOXP3, CD8, CD68, follicular lymphoma, immunohistochemistry

\section{Introduction}

Follicular lymphoma (FL) is the most common indolent B-cell lymphoma. It is generally associated with translocation $\mathrm{t}(14 ; 18)(\mathrm{q} 32 ; \mathrm{q} 21)$, which participates in tumour cell survival through overexpression of the anti-apoptotic $\mathrm{Bcl} 2$ protein $(1,2)$. Numerous treatments have been proposed, from delayed therapy after a watch-and-wait period to autologous transplantation or immune therapy, from allogenic transplantation to vaccination or the use of anti-CD20 monoclonal antibodies, with or without chemotherapy. To date, only clinical prognostic classification, such as the Follicular Lymphoma International Index (FLIPI), is used to guide treatment (3).

Accumulation of genomic alterations and clonal selection account for subsequent FL progression and transformation (4). However, a role of the FL cell microenvironment in determining clinical behaviour and disease prognosis has also recently been substantiated (5-8). In this cancer, tumour cells reside and proliferate in follicular structures in close association with helper $\mathrm{T}$ cells and follicular dendritic cells $(7,9)$. Biological analyses have been conducted to determine the exact role of these different cellular subpopulations. Staudt and Dave (10) and Dave et al (11) initially used gene expression profiling and observed a major role of T-lymphocytes and macrophages, while defining two prognostic subgroups.

Tumours induce immunologic tolerance by several mechanisms involving tolerogenic antigen-presenting cells, Foxp $3{ }^{+} \mathrm{CD} 4{ }^{+} \mathrm{CD} 25^{+}$regulatory $\mathrm{T}$ cells (Tregs). An increased frequency of Tregs has been noted in the peripheral blood of patients with bronchial carcinoma as compared to healthy individuals (12), and similar findings were also reported in patients with a variety of cancer types. Tregs that are found within the tumour microenvironment are highly suppressive and abrogate the effector function of cytotoxic $\mathrm{T}$ cells as well as NK cell-mediated cytotoxicity (13).

In follicular lymphoma, $\mathrm{FOXP}^{+} \mathrm{T}$ cells were first suggested to be associated with poor survival (14). Then conflicting results were published indicating the positive impacts of the $\mathrm{CD} 4{ }^{+} \mathrm{CD} 25^{+} \mathrm{FOXP} 3^{+}$phenotype (15-17). In addition, $\mathrm{CD} 8$ and $\mathrm{CD} 4 \mathrm{~T}$ cells were mentioned as being key cells in the progression and/or transformation process $(18,19)$, and mast cells were 
found to be associated with a poor outcome (20). Some studies have outlined the unfavourable outcome of FL associated with high numbers of tumour-associated macrophages, with or without rituximab treatment (21-23)

We thus conducted immunohistochemical analyses to investigate the presence of $\mathrm{CD}^{+} \mathrm{T}$ cells, $\mathrm{FOXP} 3^{+}$regulatory $\mathrm{T}$ cells and macrophages in follicular lymphoma, while focusing particularly on their intra- vs. interfollicular localisation. To obtain a more dynamic picture of the immune response, we correlated the $\mathrm{CD}^{+} /$Treg ratio in these two compartments with clinical parameters and outcome.

\section{Materials and methods}

Patients and samples (Table I). Fifty-eight patients consecutively diagnosed at a single institution between 1990 and 2005 were included in the present study. All cases were reviewed according to criteria of the WHO Classification (24). We observed 39 grade $1(67 \%), 10$ grade $2(17 \%)$ and 9 grade 3 (16\%) tumours. The median age of the patients was 58 years (interquartile range, 48-69 years), and the male/female ratio was 32/26. Advanced stage (Ann Arbor IV) lymphomas were noted in 14 cases (24\%). The population distribution according to FLIPI was as follows: 21 low risk cases (36\%), 26 intermediate risk cases (45\%) and 11 high risk cases (19\%).

All patients were treated with combination chemotherapy without rituximab. Thirty-two patients were in complete remission (CR) and two in partial remission (PR). Twenty-four patients died after a median follow-up of 2 years (range 1-9). The median survival was 8.5 years. Fifteen samples were identified from patients whose survival was less than 5 years, and 14 samples were identified from patients whose survival was more than 10 years after diagnosis. In addition to the diagnostic tissue samples, specimens at relapse were available for 26 patients. Ten reactive lymph nodes were used as controls.

Immunohistochemistry. Tissue samples were formalin-fixed and paraffin-embedded. Sections $(4-\mu \mathrm{m})$ were dewaxed and blocked in a hydrogen peroxide/methanol solution. Antigen retrieval was performed by heating the slides in EDTA (Sigma) (diluted 1/10, pH 7.0) at $100^{\circ} \mathrm{C}$. All immunohistochemical staining was carried out manually using anti-CD8 (clone C8/144B, Dako; dilution 1/25), anti-CD68 (KP1, Dako; dilution 1/500) and anti-FoxP3 (236A/E7, CliniSciences; dilution 1/150). Detection was performed with the Dako Real ${ }^{\mathrm{TM}}$ detection system, using peroxidase/DAB+ (ref. 5001).

CD8, CD68 and FOXP3-positive cells were counted in 20 $\mathrm{HPF}$ and expressed as the number of cells $/ \mathrm{mm}^{2}$. Positive infiltrating cells were counted independently in perifollicular and follicular (germinal centre and mantle zone) compartments. A minimum of six different follicular and interfollicular areas were selected in tumours to minimize the heterogeneous distribution of positive cells.

Double-labelling immunohistochemistry for CD8 and Foxp3 was performed in selected cases using the Benchmark $\mathrm{XT}$ automated stainer. After pretreatment as described above, the sections were exposed to CD8 (clone C8/144B, Dako, at a 1:25 dilution). The ultraView Universal DAB detection system was used with DAB chromogen. The sections were then processed for the Foxp3 antibody at a 1:100 dilution with the
Table I. Patient characteristics at diagnosis.

\begin{tabular}{lc}
\hline & No $(\%)$ \\
\hline No. of patients & \\
$\quad$ Female & $26(45)$ \\
$\quad$ Male & $32(55)$ \\
$\quad$ Total & $58(100)$ \\
Histological grade & \\
I & $39(37)$ \\
II & $10(17)$ \\
III & $9(16)$ \\
Stage & \\
I & $11(19)$ \\
II & $11(19)$ \\
III & $17(29)$ \\
IV & $19(32)$ \\
Status & \\
Dead & $24(42)$ \\
Living & $34(58)$ \\
Clinical reponse & \\
CR & $30(52)$ \\
PR & $26(3)$ \\
Not reached & \\
FLIPI & $23(45)$ \\
Low risk & $11(19)$ \\
High risk & \\
Not reached & \\
\hline &
\end{tabular}

alkaline phosphatase-based ultraView Red detection system and Fast Red/Naphthol chromogen.

Statistical analysis. The population characteristics were described with proportions for categorical variables and median and interquartile values for continuous unusually distributed variables (Shapiro-Wilk statistics). The immunochemical results were compared according to the clinical features using the Mann-Whitney U test. The Kaplan-Meier method was used to provide estimates of probability of survival. The following period was defined as time from diagnosis to time of last follow-up or death. The survival and potential prognostic factors were compared with the log rank test after conversion of the immunochemical variables into dichotomous variables using the median value. In all of the statistical analyses, $\mathrm{p}<0.05$ was considered significant. All statistical analyses were performed using SAS software (SAS Institute, Cary, NC, USA).

\section{Results}

Immunohisochemistry (IHC) results. In FL at diagnosis, CD8, POXP3 and CD68-positive cells were more numerous in interfollicular than in follicular locations: $155.35,86$ and $96.2 / \mathrm{mm}^{2}$ compared with $33.5,39.35$ and $39.25 / \mathrm{mm}^{2}$, respectively (Table II). An example is illustrated in Fig. 1. The CD8/ 
Table II. CD8, FOXP3 and CD68 immunostaining in 58 FL patients and 10 reactive lymph nodes.

\begin{tabular}{|c|c|c|c|c|c|}
\hline & Location & $\begin{array}{l}\mathrm{CD} 8+\text { cells/mm² } \\
\text { median (IQ 25-75) }\end{array}$ & $\begin{array}{l}\text { FOXP3 }^{+} \text {cells } / \mathrm{mm}^{2} \\
\text { median (IQ 25-75) }\end{array}$ & $\begin{array}{l}\mathrm{CD}^{+}{ }^{+} \text {cells } / \mathrm{mm}^{2} \\
\text { median (IQ 25-75) }\end{array}$ & Ratio CD8/FOXP3 \\
\hline \multirow[t]{2}{*}{ FL patients } & Follicular & $33.50(20.4-61.0)$ & $39.35(23.6-55.8)$ & $39.25(29.4-54.3)$ & 1.04 \\
\hline & Interfollicular & $155.35(118.8-359.2)$ & $86.00(64.0-164.0)$ & $96.20(78.2-130.8)$ & 1.66 \\
\hline \multirow{2}{*}{$\begin{array}{l}\text { Reactive lymph } \\
\text { nodes }\end{array}$} & Follicular & 25 & 8 & 14 & 2.49 \\
\hline & Interfollicular & 411 & 150 & 235 & 4.07 \\
\hline
\end{tabular}

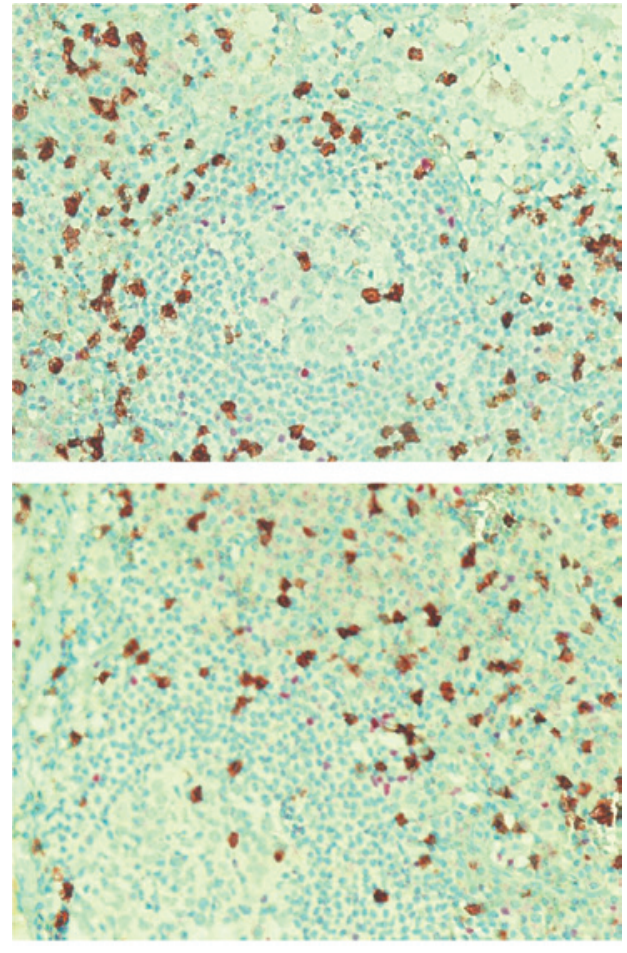

Figure 1. Immunohistochemical double-staining patterns in two FL cases FoxP3 (regulatory T cells)-positive cells are shown in red and CD8-positive cells are in brown.

FOXP3 median ratio was 1.66 in interfollicular locations compared with 1.04 in follicular locations.

In reactive lymph nodes, the CD8/FOXP3 median ratio was higher than that in FL, both in interfollicular (4.07 vs. 1.66) and follicular locations (2.49 vs. 1.04). (Table II).

Correlations between IHC results and clinical features. The interfollicular and follicular CD8/Treg ratios were compared with the main clinical features of the patients at diagnosis. The interfollicular CD8/FOXP3 ${ }^{+}$cell ratio was significantly higher in patients with grade 3 tumours (2.04 vs. 1.63) and with a high risk FLIPI index (2.99 vs. 1.53) compared with those with grade 1-2 tumours or a low-intermediate FLIPI index. The same results were obtained with the follicular $\mathrm{CD}^{+} /$ $\mathrm{FOXP}^{+}$cell ratio (Table III). We did not note any significant relationship with stage or patient age.

Correlations between IHC results and outcome. Concerning the interfollicular $\mathrm{FOXP}^{+}$cell number, more than 86 cells/

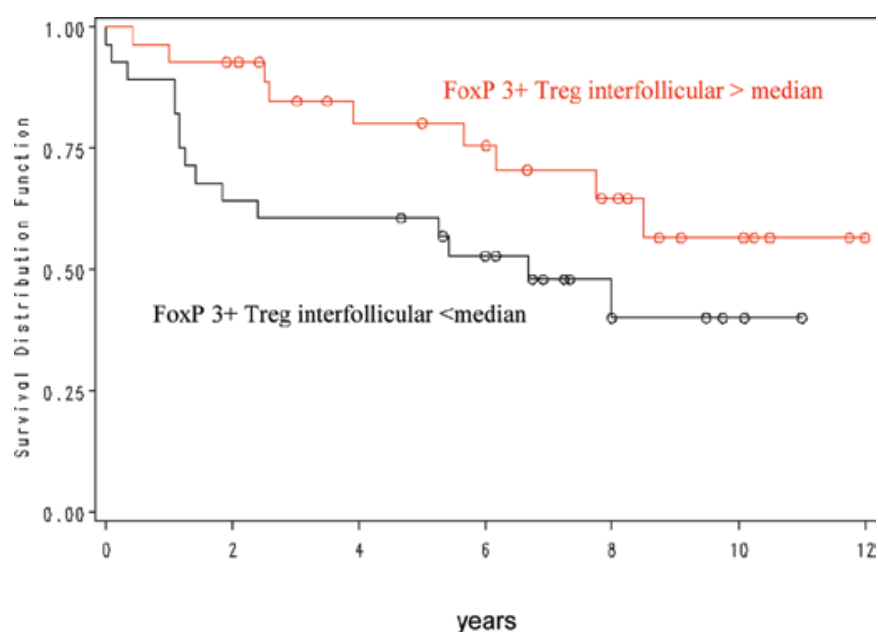

Figure 2. Overall survival in patients with FL in relation to FoxP3-positive interfollicular cells

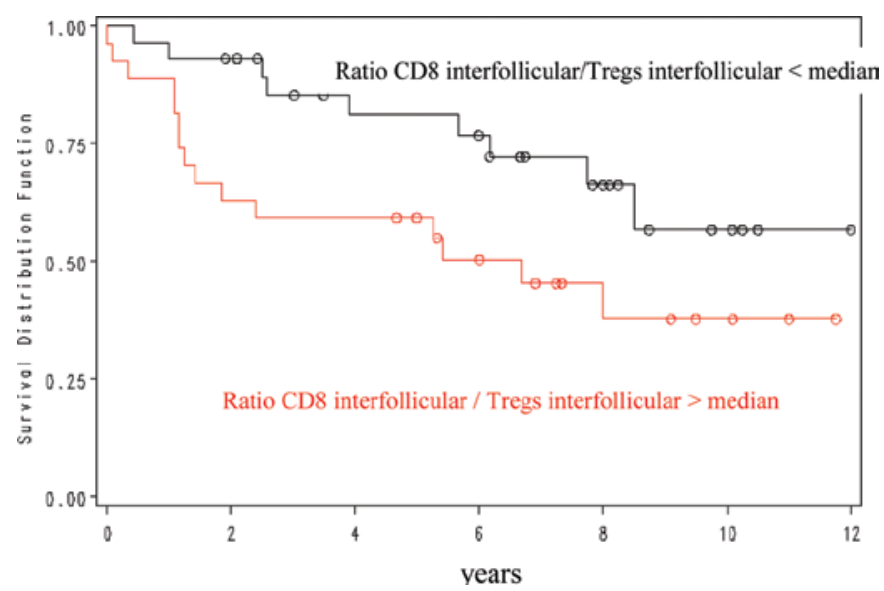

Figure 3. Overall survival in patients with FL in relation to the interfollicular CD8/FoxP3 ratio.

$\mathrm{mm}^{2}$ were correlated with a more favourable outcome $(\mathrm{p}=0.03)$ (Fig. 2). In contrast, intrafollicular FOXP3, intrafollicular and interfollicular CD8 and CD68 cell numbers were not predictive of patient outcome.

The interfollicular CD8/FOXP3 ratio showed a positive prognostic value for overall survival, with a 5-year OS of 82 vs. $59 \%$ for a ratio of less or more than 1.68 (Fig. 3). Other ratios were not significantly correlated with outcome. 
Table III. Relationship between CD8/FOXP3 ${ }^{+}$cell ratio and clinical features.

\begin{tabular}{lccc}
\hline Expressed in median (IQ 25-75) & Grade 1 and 2 $(\mathrm{n}=49)$ & Grade 3 $(\mathrm{n}=9)$ & P-value \\
\hline Follicular CD8/FOXP3+ cell ratio & $0.886(0.47-1.54)$ & $3.463(1.66-4.01)$ & 0.002 \\
Interfollicular CD8/FOXP3 ${ }^{+}$cell ratio & $1.634(1.02-2.29)$ & $2.048(1.65-3.66)$ & 0.050 \\
\hline & $\begin{array}{c}\text { FLIPI low and intermediate } \\
\text { risk }(\mathrm{n}=47)\end{array}$ & FLIPI high risk $(\mathrm{n}=11)$ & \\
& $0.916(0.48-1.57)$ & $2.091(1.08-8.04)$ & 0.020 \\
\hline $\begin{array}{l}\text { Follicular CD8/FOXP3 } \\
\text { Interfollicular CD8/FOXP3 }{ }^{+} \text {cell ratio }\end{array}$ & $1.536(1.02-2.01)$ & $2.993(1.762-8.676)$ & 0.001 \\
\hline
\end{tabular}

Table IV. CD68, CD8 and POXP3-positive cells at first relapse compared with at diagnosis.

\begin{tabular}{|c|c|c|c|}
\hline Expressed in median (IQ 25-75) & Diagnosis $(\mathrm{n}=58)$ & Relapse $(n=26)$ & P-value \\
\hline Follicular CD68 ${ }^{+}$cells $/ \mathrm{mm}^{2}$ & $39 \quad(29.4-54.3)$ & $32(20.5-46.8)$ & 0.007 \\
\hline Interfollicular CD68 ${ }^{+}$cells $/ \mathrm{mm}^{2}$ & $96 \quad(86.2-112.8)$ & $62(54.1-73.2)$ & 0.005 \\
\hline Interfollicular $\mathrm{CD} 8 / \mathrm{FOXP}^{+}$cell ratio & $1.66(1.07-2.26)$ & $2.2(1.32-3.87)$ & 0.050 \\
\hline
\end{tabular}

CD8, CD68 and FOXP3-positive cells in FL at first relapse compared with at diagnosis. When comparing these two groups, we observed a significant difference between the number of CD68 cells in intrafollicular (39.23 at diagnosis vs. 32 at relapse, $\mathrm{p}=0.07$ ) and interfollicular locations (96 at diagnosis vs. 62 at relapse, $\mathrm{p}=0.06$ ). The $\mathrm{CD} 8 / \mathrm{FOXP} 3$ ratio in interfollicular locations was significantly different (1.66 at diagnosis vs. 2.2 at relapse, $\mathrm{p}=0.05$ ) (Table IV).

\section{Discussion}

The present study of 58 diagnostic lymph node samples from FL patients showed that the interfollicular $\mathrm{CD} 8 / \mathrm{FOXP} 3^{+}$cell ratio was significantly higher in patients with grade 3 tumours (2.04 vs. 1.63) and with a high risk FLIPI index (2.99 vs. 1.53) compared with those with grade 1-2 tumours or a lowintermediate FLIPI index. We obtained the same results with the follicular $\mathrm{CD}^{+} / \mathrm{FOXP}^{+}$cell ratio. Moreover, the interfollicular CD8/FOXP3 ratio was found to have a prognostic value for overall survival, with a 5-year OS of 82 vs. 59\% for a ratio of less or more than 1.68. An interfollicular FOXP3 $3^{+}$cell number of more than 86 cells $/ \mathrm{mm}^{2}$ was correlated with a more favourable outcome $(\mathrm{p}=0.03)$.

These results are in accordance with the findings of two recent studies in which a perifollicular pattern of FOXP3positive cells was more commonly found in the diagnosis of FL lymph nodes from patients whose subsequent outcome was favourable $(15,17)$. Tzankov et al reported a favourable prognostic influence of an increased amount of $\mathrm{FOXP}^{+}$cells in $\mathrm{FL}$, cHL and in GC-like diffuse large B-cell lymphomas, and defined a cutoff value of $88.6 \mathrm{FOXP}^{+}$cells $/ \mathrm{mm}^{2}$ in a ROC analysis (16). These authors did not take the interfollicular vs. follicular location into account. In our study, an interfollicular but not follicular FOXP3 ${ }^{+}$cell number of more than 86 cells/ $\mathrm{mm}^{2}$ was correlated with a more favourable outcome $(\mathrm{p}=0.03)$.
Recent studies have shown that tumour B cells alone induce conventional $\mathrm{T}$ cells to express FOXP3 and acquire a regulatory function (25). The presence of FOXP3-positive cells is also a protective variable in classical Hodgkin's disease in which an inverse relationship between TIA-1 and FOXP3 expression and survival has been demonstrated. Moreover, higher levels of FOXP3 twinned with low TIA-1 were beneficial $(16,26,27)$. In a recent study, De Jong et al showed that the presence of $\mathrm{CD} 4 / \mathrm{FOXP}^{+}$cells is beneficial to the host, irrespective of the treatment used (28).

When comparing the two groups at diagnosis and relapse, we observed a significant difference between the CD8/ FOXP3 ratio in interfollicular locations (1.66 at diagnosis vs. 2.2 at relapse, $\mathrm{p}=0.05$ ). In the Tzankov study, a 2.7 -fold (from 94 to 33/ $\mathrm{mm}^{2}$ ) proportional decrease in FOXP3 ${ }^{+}$cells in transformed DLBCL evolving from FL was observed after immunochemical screening, and this was similar to the 4.4-fold decrease observed by Carreras et al (9.6-2.2\%) (17).

Concerning the presence of $\mathrm{CD} 68^{+}$cells, we did not obtain a significant correlation with poor survival. However, a recent study outlined the influence of specific therapeutic regimens on the prognostic impact of CD68-postive macrophages in follicular lymphoma (28). Surprisingly, the numbers of CD68 cells both in intrafollicular and interfollicular locations were significantly lower at relapse as compared to the diagnostic samples (respectively 32 vs. $39.23, \mathrm{p}=0.07$ and 62 vs. 96 , $\mathrm{p}=0.05)$.

In inflammatory lymph nodes, we found an interfollicular CD8/FOXP3 ratio (2.74) close to that of the $15 \mathrm{FL}$ patients with less than a 5-year survival (2.02). These findings are in agreement with those of Glas et al, who showed that FL with a poor prognosis and a poor response to anti-CD20 therapy had gene expression signatures that were similar to that of normal activated lymphoid tissue (29). 
As proposed by De Jong, the clinical behaviour and prognosis of FL seem to be inherited rather than acquired properties according to a dual pathway model $(30,31)$. The poor prognosis pathway may be characterised by genetic alterations inducing highly activated specific $\mathrm{T}$ cells. In the 'good prognosis' pathway, different alterations (der18q and $+7 /+8)$ and additional anti-apoptotic signals are involved, so protection from apoptosis may therefore be more important than immunologic support. The findings of a recent study support this hypothesis, showing that host genetic variability in immune genes, particularly IL-8, IL-2, IL-12B and IL-1RN, appear to be associated with overall survival in FL (32).

In conclusion, the presence of a high $\mathrm{CD} 8 / \mathrm{FOXP} 3$ ratio is the hallmark of an active immune response during tumour development, with lymphoma cells acting as either target or bystander and reflecting a more aggressive disease.

\section{References}

1. Tsujimoto Y, Cossman J, Jaffe E and Croce CM: Involvement of the bcl-2 gene in human follicular lymphoma. Sciences 228: 1440-1443, 1985.

2. Clearly ML and Sklar J: Nucleotide sequence of $t(14,18)$ chromosomal breakpoint in follicular lymphoma and demonstration of a breakpoint-cluster region near a transcriptionally active locus on chromosome 18. Proc Natl Acad Sci USA 82: 7439-7443, 1995.

3. Solal-Céligny P, Roy P, Colombat P, White J, Armitage JO, Arranz-Saez R, Au WY, Bellei M, Brice P, Caballero D, Coiffier B, Conde-Garcia E, Doyen C, Federico M, Fisher RI, Garcia-Conde JF, Guglielmi C, Hagenbeek A, Haïoun C, LeBlanc M, Lister AT, Lopez-Guillermo A, McLaughlin P, Milpied N, Morel P, Mounier N, Proctor SJ, Rohatiner A, Smith P, Soubeyran P, Tilly H, Vitolo U, Zinzani PL, Zucca E and Montserrat E: Follicular Lymphoma International Prognostic Index. Blood 104: 1258-1265, 2004.

4. Lossos IS and Levy R: Higher-grade transformation of follicle center lymphoma is associated with somatic mutation of 5 noncoding regulatory region of Bcl-6 gene. Blood 96: 635-639, 2000.

5. Küppers R: Prognosis in follicular lymphoma - it's in the microenvironment. N Engl J Med 351: 2152-2153, 2004.

6. Natkunam Y: The biology of germinal center. Hemat Am Soc Hematol Educ Program: 210-215, 2007.

7. Amé-Thomas P, Maby-El Hajjami H, Monvoisin C, Jean R, Monnier D, Caulet-Maugendre S, Guillaudeeux T, Lamy T, Fest $\mathrm{T}$ and Tarte $\mathrm{K}$ : Human mesenchymal stem cells isolated from bone marrow and lymphoid organs support tumor B-cell growth: role of stromal cells in follicular lymphoma pathogenesis. Blood 109: 693-702, 2007.

8. Herreros B, Sanchez-Aguilera A and Piris MA: Lymphoma microenvironment: culprit or innocent. Leukemia 22: 49-58, 2008.

9. Carbone A, Gloghini A, Cabras A and Elia G: Differentiating germinal center-derived lymphomas through their cellular microenvironment. Am J Haematol 84: 435-438, 2009.

10. Staudt LM and Dave S: The biology of human lymphoid malignancies revealed by gene expression profiling. Adv Immunol 87: 163-208, 2005

11. Dave SS, Wright G, Tan B, Rosenwald A, Gascoyne RD, Chan WC, Fisher RI, Braziel RM, Rimsza LM, Grogan TM, Miller TP, LeBlanc M, Greiner TC, Weisenburger DD, Lynch JC, Vose J, Armitage JO, Smeland EB, Kvaloy S, Holte H, Delabie J, Connors JM, Lansdorp PM, Ouyang Q, Lister TA, Davies AJ, Norton AJ, Muller-Hermelink HK, Ott G, Campo E, Montserrat E, Wilson WH, Jaffe ES, Simon R, Yang L, Powell J, Zhao H, Goldschmidt N, Chiorazzi M and Staudt LM: Prediction of survival in follicular lymphoma based on molecular features of tumor-infiltrating immune cells. N Engl J Med 351: 2159-2169, 2004.

12. Woo EY, Chu CS, Goletz TJ, et al: Regulatory CD4+ CD25+ cells in tumors from patients with early-stage non-small cell lung cancer and late-stage ovarian cancer. Cancer Res 61: 4766-4772, 2001.
13. Shevach EM: Mechanisms of foxp $3^{+} T$ regulatory cell-mediated suppression. Immunity 30: 636-645, 2009.

14. Farinha P, Al-Tourah A, Gill K, Klasa R, Connors JM and Gascoyne RD: The architectural pattern of FOXP3-positive $\mathrm{T}$ cells in follicular lymphoma is an independent predictor of survival and histologic transformation. Blood 115: 289-295, 2010.

15. Lee AM, Clear AJ, Calaminici M, Davies AJ, Jordan S, MacDougall F, Matthews J, Norton AJ, Gribben JG, Lister TA and Goff LK: Numbers of CD4 ${ }^{+}$cells and location of forkhead box protein-P3-positive cells in diagnostic follicular lymphoma tissue microarrays correlates with outcome. J Clin Oncol 24: 5052-5059, 2006.

16. Tzankov A, Meier C, Hirschmann P, Went P, Pileri SA and Dirnhofer S: Correlation of high numbers of intratumoral FoxP3 regulatory $\mathrm{T}$ cells with improved survival in germinal centerlike diffuse large B-cell lymphoma, follicular lymphoma and classical Hodgkin's lymphoma. Haematologica 93: 193-200, 2008.

17. Carreras J, Lopez-Guillermo A, Fox BC, Colomo L, Martinez A, Roncador A, Montserrat E, Campo E and Banham AH: High numbers of tumors-infiltrating FoxP3-positive regulatory T cells with improved overall survival in follicular lymphoma. Blood 108: 2957-2964, 2006

18. Glas AM, Kersten MJ, Delahaye L, Witteveen AT, Kibbelaar RE, Velds A, Wessels LA, Joosten P, Kerkhoven RM, Bernards R, Van Krieken JH, Kluin PM, van't Veer LJ and de Jong D: Gene expression profiling in follicular lymphoma to assess clinical aggressiveness and to guide the choice of treatment. Blood 105: 301-307, 2005

19. Engelbrekt W, Sander B, Christensson B and Kimby E: CD8+ T-cell content in diagnostic lymph nodes measured by flow cytometry is a predictor of survival in follicular lymphoma. Clin Cancer Res 13: 388-397, 2007.

20. Taskinen M, Karjalainen-Lindsberg ML and Leppä S: Prognostic influence of tumor-infiltrating mast cells in patients with follicular lymphoma treated with rituximab and CHOP. Blood 111: 4664-4667, 2008.

21. Alvaro T, Lejeûne M, Salvado MT, Lopez C, Jaén J and Bosch R: Immunohistochemical patterns of reactive microenvironment are associated with clinicobiologic behavior in follicular lymphoma patients. J Clin Oncol 24: 5350-5357, 2006.

22. Taskinen M, Karjalainen-Lindsberg ML, Nyman $H$, Eerola LM and Leppä S: A high tumor-associated macrophage content predicts favorable outcome in follicular lymphoma patients treated with rituximab and cyclophosphamidedoxorubicin-vincristine-prednisone. Clin Cancer Res 13: 5784-5789, 2007.

23. Canioni D, Salles G, Mounier N, Brousse N, Keuppens M, Morchhausser F, Lamy T, Sonnet A, Rousselet MC, Foussard C and Xerri L: High numbers of tumor-associated macrophages have an adverse prognostic value that can be circumvented by rituximab in patients with follicular lymphoma enrolled onto the GELA-GOELAMS FL-2000 trial. J Clin Oncol 26: 440-446, 2008.

24. Swerrdlow SH, Campo E, Lee Harris N, Jaffe E, Pileir A, Stein $\mathrm{H}$, Thiel $\mathrm{J}$ and Vardiman $\mathrm{J}$ : WHO Classification of Tumours of Haematopoietic and Lymphoid Tissues. 4th edition. International Agency for Research on Cancer, 2008.

25. Ai W, Hou JZ, Zeiser R, Czerwinski D, Negrin RS and Levy R: Follicular lymphoma B cells induce the conversion of conventional $\mathrm{CD}^{+}{ }^{+}$cells to T-regulatory cells. Int J Cancer 124 : 239-244, 2008

26. Alvaro T, Lejeune M, Salvado MT, Bosch R, Garcia JF, Jaén J, Banham AH, Roncador G, Montalban C and Piris M: Outcome in Hodgkin's lymphoma can be predicted from the presence of accompanying cytotoxic and regulatory $\mathrm{T}$ cells. Clin Cancer Res 11: 1467-1473, 2005.

27. Chetaille B, Bertucci F, Finetti P, Esterni B, Stamatoullas A, Picquenot JM, Copin MC, Morschhauser F, Casasnovas O, Petrella T, Molina T, Vekhoff A, Feugier P, Bouabdallah R, Birnbaum D, Olive D and Xerri L: Molecular profiling of classical Hodgkin lymphoma tissues uncovers variations in the tumor microenvironment and correlations with EBV infection and outcome. Blood 113: 2765-3775, 2009.

28. De Jong D, Koster A, Hagenbeek A, Reameakers J, Veldhuizen D, Heisterkamps S, De Boer JP and Vanglabeeke M: Impact of tumor microenvironment on prognosis in follicular lymphoma is dependent on specific treatment protocols. Haematologica 94: 70-77, 2009. 
29. Glas AM, Kersten MJ, Delahaye LJ, Witteveen AT, Kibbelaar RE, Velds A, Wessels LF, Joosten P, Kerkhoven RM, Bernards R, van Krieken JH, Kluin PM, van 't Veer LJ and De Jong D: Gene-expression and immunohistochemical study of specific T-cell subsets and accessory cell types in the transformation and prognosis of follicular lymphoma. J Clin Oncol 25: 390-398, 2007.

30. De Jong D: Molecular pathogenesis of follicular lymphoma: A cross talk of genetic and immunologic factors. J Clin Oncol 23: 6358-6363, 2005.
31. Kelley T, Beck R, Absi A, Jin T, Pohlman B and Hsi E: Biologic predictors in follicular lymphoma: importance of markers of immune response. Leuk Lymphoma 48: 2403-2411, 2007.

32. Glas AM, Kersten MJ, Delahaye LJ, Witteveen AT, Kibbelaar RE, Velds A, Wessels LF, Joosten P, Kerkhoven RM, Bernards R, van Krieken JH, Kluin PM, van 't Veer LJ and de Jong D: Prognostic significance of host immune gene polymorphisms in follicular lymphoma survival. Blood 109: 5439-5446, 2007. 